\title{
Liderança feminina: percepções, reflexões e desafios na administração pública
}

\author{
Renata Kessler Miltersteiner ${ }^{1}$ \\ FÁTIMA BAYMA DE OLIVEIRA ${ }^{2}$ \\ LYGIA GONÇALVES COSTA HRYNIEWICZ ${ }^{3}$ \\ ANDERSON DE SOUZA SANT'ANNA ${ }^{4}$ \\ LUIZ CARLOS MOURA ${ }^{2}$
}

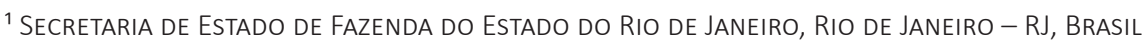 \\ 2 Fundação Getulio Vargas (FGV EBAPE) / Escola Brasileira de AdMinistração Pública E de EMPresas, RIO de JANEIRO - RJ, BRASIL \\ ${ }^{3}$ Universidade Federal do Rio de JANEIRO (UFRJ) / NuCleo de PESQUISA EM ESTRATIFICACAO E TRAJETORIAS SOCIAIS, RIO DE JANEIRO - RJ, BRASIL \\ ${ }^{4}$ FundaçÃo Getulio Vargas (FGV EAESP) / Escola de Administração de EMPresas de SÃo Paulo, SÃo Paulo - SP, Brasil
}

\section{Resumo}

A discriminação sofrida pelas mulheres em posições estratégicas é fato recorrente no mercado de trabalho, em particular no Brasil. Mesmo que, geralmente, elas possuam maior qualificação que os homens, isto não se reflete nos seus salários e nos cargos por elas ocupados. As causas de tais limitações possuem raízes históricas, sociais e psicológicas. Neste artigo objetiva-se melhor compreender desafios enfrentados na ocupação de posições de liderança por mulheres na administração pública do executivo brasileiro, tendo por base barreiras comumente descritas na literatura internacional e nacional sobre o tema do alcance de postos de liderança - "teto de vidro", "labirintos de liderança", "abelha rainha". Metodologicamente, o estudo compreende duas etapas. A primeira, de abordagem qualitativa, compreende entrevistas semiestruturadas e em profundidade com lideranças - Subsecretárias - da Administração Pública do Rio de Janeiro. Na segunda fase, quantitativa, fez-se uso de survey, aplicado a gestoras da Secretaria de Estado de Fazenda e Planejamento Fluminense. Nos resultados, constata-se que a mulher ainda sofre preconceitos e enfrenta barreiras associadas aos códigos masculinos de ascensão profissional. Ainda assim, a maioria das entrevistadas indica não sofrer preconceito direto, afirmando o crescimento e o alcance de posições estratégicas por méritos próprios.

Palavras-chave: Liderança feminina. Carreira feminina. Administração pública. Igualdade de oportunidade.

\section{Female leadership: perceptions, reflexions, and challenges in public administration}

\begin{abstract}
Discrimination against women in strategic positions is a recurring issue in the labor market, particularly in Brazil. Even though women generally have higher qualifications than men, this is not reflected in their salaries or positions. The causes of such limitations have historical, social, and psychological roots. This article aims to understand better the challenges faced by women in the public administration of the Brazilian executive branch. The study is based on the barriers to reaching leadership positions, such as "Glass Ceiling," "Leadership Labyrinths," and "Queen Bee," commonly described in the international and national literature on the theme. The study is organized in two stages. In the first, a qualitative approach was adopted, involving semi-structured and in-depth interviews with leaders - Under Secretaries - working in the government of the State of Rio de Janeiro. The second stage adopted a quantitative approach, with a questionnaire applied to female managers working at the State Secretariat of Finance and Planning of Rio de Janeiro. As a result, it appears that women still suffer from prejudices and barriers associated with male codes of professional advancement. However, most women indicate no direct prejudice, claiming that they have grown and reached strategic positions on their own merits.
\end{abstract}

Keywords: Female leadership. Women's career. Public administration. Equal opportunity.

\section{Liderazgo femenino: percepciones, reflexiones y desafíos en la administración pública}

\section{Resumen}

La discriminación de mujeres en cargos estratégicos es un hecho recurrente en el mercado laboral, en particular, en Brasil. Aunque, generalmente, las mujeres cuentan con una mayor cualificación que los hombres, eso no se refleja en los sueldos y en los puestos por ellas ocupados. Las causas de dichas limitaciones tienen raíces históricas, sociales y psicológicas. El objetivo de este artículo es comprender mejor los desafíos enfrentados por las mujeres para ocupar posiciones de liderazgo en la Administración Pública del Poder Ejecutivo brasileño, tomando como base barreras comúnmente descritas en la literatura internacional y nacional disponible sobre el tema puestos de liderazgo - "Techo de cristal", "Laberintos del liderazgo", "Abeja reina"-. Metodológicamente, el estudio consta de dos etapas. La primera, de abordaje cualitativo, incluye entrevistas semiestructuradas y en profundidad a liderazgos -Subsecretarias- de la Administración Pública de Río de Janeiro. En la segunda fase, cuantitativa, se hicieron surveys a gestoras de la Secretaría de Estado de Hacienda y Planificación Fluminense. Como resultado, se constata que la mujer todavía es víctima de prejuicios y barreras asociados a códigos masculinos de ascenso profesional. Sin embargo, la mayoría indica no sufrir prejuicios directos y afirma haber crecido y alcanzado cargos estratégicos por sus propios méritos.

Palabras clave: Liderazgo femenino. Carrera femenina. Administración Pública. Igualdad de oportunidades. 


\section{INTRODUÇÃO}

Um marco importante no processo de inserção feminina no mercado de trabalho é a Revolução Industrial (séculos XVIII e XIX). As condições de trabalho eram precarias, sobretudo para as mulheres e crianças. No entanto, mal sabiam que a partir do século XX portas se abririam para reivindicações de posições na esfera política, organizacional e educacional (MELO e THOMÉ, 2018).

No pós-guerra, as conquistas femininas no mercado de trabalho ganham maior evidência, trazendo à tona a questão da divisão sexual do trabalho como tema relevante a ser estudado pela academia e pelo mercado. A compreensão e as respostas à situação de inferioridade feminina no âmbito do trabalho serão, então, buscadas por correntes de pensamento político e econômico, sobretudo, as liberais e as marxistas. Para o feminismo liberal, a subordinação da mulher decorre do processo histórico-cultural, no qual a mulher se vê doutrinada a cuidar da prole e a ser submissa, cabendo aos homens ser os senhores da razão e responsáveis pelo sustento da família. Para que tal estrutura se modifique, recomenda-se a inserção incisiva da mulher no campo de trabalho, a fim de que ela seja vista pela sociedade como ser atuante e socialmente relevante. A abordagem liberal sustenta a ideia de que homens e mulheres são iguais entre si e perante a lei, do que decorre logicamente que lhes cabem os mesmos direitos. Sob tal perspectiva, o significado de feminismo se liga à conquista por "direitos iguais" - como a luta desencadeada pelas "sufragistas" norte-americanas -, sendo esta abordagem, no entanto, mais voltada para o indivíduo do que para o coletivo (MELO e THOMÉ, 2018). O movimento liberal questiona, ainda, a rotulação por parte da sociedade da divisão sexual homem-mulher, propondo a meritocracia como caminho de dissolução das diferenças, pelo qual considera-se, prioritariamente, o grau de capacidade do indivíduo, seja ele homem ou mulher.

Sob a perspectiva marxista, teorias feministas acusam o capitalismo de perpetuar a dominação masculina, sobretudo, em relacão ao controle dos meios de produção pela violência. Para Haraway (2004), os homens estariam intrinsecamente ligados ao processo produtivo, ascendendo sem barreiras na vida pública, deixando às mulheres o papel de cuidar da família e do lar. À figura feminina é, portanto, atribuído papel restrito na atuação social, assegurando ao homem espaço garantido no mercado de trabalho e na esfera pública. Para garantir o fim de relacões desiguais, torna-se necessária uma transformação radical, sobretudo nas relações socioeconômicas (MELO e THOMÉ, 2018).

Segundo Oliveira (1993), apesar dos direitos conquistados na esfera das relações de trabalho, da crescente defesa em torno da empregabilidade feminina, bem como da melhoria dos seus níveis de qualificacão, as mulheres iniciam o século XX em condicão de inferioridade em comparação com trabalhadores homens. Hirata e Kergoat (2017) afirmam que a ideia de uma divisão sexual do trabalho começa a ganhar espaço após lutas feministas pelo reconhecimento do trabalho doméstico.

Nesse contexto, pesquisas são direcionandas à participação igualitária da mulher no mercado de trabalho formal. Contudo, quando se compara a participação dos dois gêneros no mercado de trabalho remunerado, observa-se a predominância masculina, sobretudo em cargos de lideranca (MELO e THOMÉ, 2018, p. 112). Para Scott (1986), a mobilidade ocupacional leva as mulheres a práticas como a imitação das atitudes masculinas. Ao buscar equiparar-se aos homens, passam a atrair os olhares sobre as diferenças.

Não apenas no mercado de trabalho, como nas atividades domésticas, ainda persistem manifestações de poder e dominação que homens exercem ao longo da história, embora hoje, mais sutis. Apesar de possibilidades prescritas em lei para o acesso de mulheres, inúmeras situações de discriminação são mantidas, indicando que quanto à igualdade de direitos ainda há um longo caminho a ser percorrido (BETIOL, 2000; CARVALHO, CARVALHO e CARVALHO, 2001; HURLEY, 1999; MARVIN e BRYANS, 1999;).

Outro fato é a falta de confiança que as mulheres têm em si, somada à cultura de superioridade do homem como influenciador no modo como ela se percebe e é percebida pelo mercado (HRYNIEWICZ e VIANNA, 2018). Notadamente, os homens possuem maior espaço na vida social, sendo considerados representantes das famílias e responsáveis pela manutenção financeira, fato que vem sofrendo mudanças, mas a passos lentos.

A participação da mulher na sociedade brasileira como ser atuante é consagrada apenas pela Constituição de 1934, quando legalmente, elas passam a exercer o direito de voto (OLIVEIRA, MENEZES e SANT'ANNA, 2012). Forma-se assim, embora tardiamente, a tríade mulher, mercado de trabalho e política, fator importante na conjectura política do país. Ademais, por mais independente financeiramente que a mulher se torne, ela ainda não alcança uma independência social e psicológica, uma vez que a sociedade ainda a percebe como secundária (KANAN, 2010). 
Nesse sentido, este estudo torna-se relevante ao considerar que, não obstante os cargos de direção serem ocupados em sua maioria por homens, comprovadamente, hoje, as mulheres são maioria em cursos superiores, principalmente na área da educação (MELO e THOMÉ, 2018). Dados da Pesquisa Nacional por Amostra de Domicílio - PNAD (IBGE, 2017) indicam que as mulheres são as que mais estudam: 9,3 anos; homens, 8,9 anos. Ao verificar a taxa ajustada de frequência escolar líquida ao ensino superior, constata-se um índice de $26,8 \%$ em relação às mulheres, enquanto para os homens tal porcentagem é de 19,7\%, valor estável em relação a 2016.

Por estudarem mais, acredita-se que elas possuam maior conhecimento técnico para o exercício de cargos de direção e de gerência. A Administração Pública, nesse sentido, deveria reproduzir melhor esse fato, haja vista a admissão por concurso. A propósito, o conhecimento técnico é percebido como um aliado das gestoras no alcance de cargos de alto escalão.

O que se pode observar deste conjunto de acontecimentos é que o feminismo jamais focou na superioridade da mulher, diferentemente, ele enfatiza a equidade e a justiça social no mercado de trabalho. Nesse contexto, um dos temas mais sensíveis à inserção das mulheres no mercado de trabalho é o da liderança feminina. Aos poucos as mulheres alcançam postos de gestão e poder, tornam-se líderes, e suas atitudes motivam um número crescente de pesquisadores a uma melhor compreensão do fenômeno.

\section{FUNDAMENTAÇÃO TEÓRICA}

\section{Gênero, organizações e trabalho}

Segundo Irigaray (2011), é natural que as empresas, a fim de atingir suas metas financeiras, defendam um ambiente administrativo mais funcional e neutro, silenciando, dessa forma, a emergência das minorias. No entanto, é dificil negar que a força de trabalho nas organizacões tem-se diversificado em termos de gênero, confrontando o ideal de neutralidade e tecnicismo, bem como a postura de homogeneidade dessas organizações. Neste sentido, a discussão sobre as diferenças de gênero nas organizacões continuam atuais e necessárias, sobretudo, na medida em que quanto mais as organizações aprendem sobre tais diferenças, mais elas podem ampliar sua performance e aumentar as oportunidades de mercado.

É importante iniciar a discussão reconhecendo a sua amplitude, uma vez que gênero não se retringe à anatomia, mas se relaciona também à maneira como o indivíduo se identifica ou se expressa socialmente. A biologia pode identificar o sexo de um indivíduo conforme suas células reprodutivas, no entanto, ao estabelecer categorias e tipificações entre homens e mulheres, o tema deixa de ser puramente biológico, passando a se configurar também culturalmente (JESUS, 2012).

Nesse contexto, as mulheres lutam para superar a condição de minoria; há décadas empenham-se para serem reconhecidas nas mais diversas instâncias da sociedade, em especial, nas organizações, que apesar de "modernizadas", ignoram a necessidade de políticas e práticas de gestão baseadas na diversidade, no sentido amplo do termo (SIQUEIRA, SALES e FISCHER, 2016).

No Brasil, nota-se certo caráter pragmático na regulamentação e condução de políticas de diversidade no âmbito organizacional, pois as empresas parecem limitar-se a medidas que respondem ao número de vagas estabelecido pela legislação. A discussão é delicada, evidenciando que práticas de gestão em torno da diversidade não necessariamente garantem a aderência das organizações à causa, nem tampouco a inclusão efetiva de grupos minorizados.

De acordo com Pérez-Nebra e Torres (2014, p. 528), não se pode ignorar que a inclusão se dá além da diversidade, que "[...] sua concretização depende da gestão da diversidade de modo a criar um ambiente organizacional que possibilite a todos o pleno desenvolvimento de seu potencial na realização dos objetivos da empresa". Em outras palavras, inclusão é uma conquista em termos de tratamento, convivência e confiança estabelecida com outros trabalhadores nas organizações.

Como resultante, torna-se fundamental traçar um caminho de inclusão mais aderente aos modelos de negócios, permitindo sua assimilação de forma mais orgânica e estratégica. Em suma, a diversidade deve ser compreendida e não instrumentalizada, permitindo que a cultura organizacional e os estilos de trabalho e liderança sejam ressignificados (SIQUEIRA, SALES e FISCHER, 2016). O discurso praticado pelas organizações com relacão a diversidade e inclusão não pode ser apenas focado em resultados imediatos, mas no seu teor ético e moralmente justo, indispensáveis à função social das organizações. 


\section{Mulher e liderança}

Conforme observa Teixeira (1998), a liderança pode ser entendida como "[...] o processo de influenciar outros de modo a conseguir que façam o que o líder quer que seja feito, ou ainda, a capacidade de influenciar um grupo a atuar no sentido da prossecução dos objetivos do grupo". Cabe ressaltar, portanto, que nem todo gestor é líder. Pode-se ter um gestor de fato, mas não um líder de direito, uma vez que a liderança é intrínseca.

Muito embora sendo um tema sensível ao estudo das organizações, as questões de gênero também têm sido abordadas em estudos sobre a liderança. Para Nogueira (2012), o foco da cultura em pessoas e a facilidade de comunicação da mulher são retratados como competências em liderança comumente associadas à figura feminina.

No que diz respeito às mulheres, observa-se a busca por se posicionar em ocupações mais estratégicas, tendo em vista a melhor escolarização e formação técnica, não raro, mais elevada. Todavia encontram como barreiras o estilo de liderança masculino.

Na medida em que, no entanto, a sociedade passa a se pautar, pelo menos no nível do discurso, na maior importância da subjetividade humana - desejo, inovação, criatividade, "brilho nos olhos" -, no processo produtivo, discussões em torno de um estilo "feminino de liderança" ganham espaço. Na prática, porém, não é simples para a mulher gestora seguir um estilo de liderança feminino. Elas, comumente, esbarram em preconceitos, estereótipos de gênero e nas formas de agir e de avaliação das organizações.

Nesse sentido, as mulheres vivenciam paradoxos do tipo double-bind: se o seu comportamento for feminino, é esteriotipado como ineficaz; se empregam comportamentos mais "assertivos" tendem à masculinizacão, prejudicando ainda mais sua imagem social (NOGUEIRA, 2012). Em resumo, vive-se um dilema quanto ao estilo de liderança. Para retratar tal ambiguidade o discurso acadêmico se vale de metáforas, dentre elas as de "labirinto de liderança" e "síndrome da abelha rainha".

\section{Barreiras à liderança feminina}

À clássica metáfora do "teto de vidro" (glass ceiling), apesar de muito empregada no meio acadêmico, vem agregando-se a outras, dentre elas a metáfora do "labirinto", direcionada a investigar as várias barreiras que as mulheres enfrentam ao buscar ocupar cargos de níveis mais estratégicos (HRYNIEWICZ e VIANNA, 2018; OLIVEIRA, MENEZES e SANT'ANNA, 2012). Dentre tais barreiras, Eagly e Carly (2007) fazem menção a cinco principais: preconceito; resistência à liderança feminina; estilo de liderança; demandas da vida familiar; capital social.

Já autores como Arvatea, Galileab e Todescatc (2018) e Derks, Van Laarb e Ellemers (2016) recorrem à metáfora da "abelha rainha" para ilustrar os desafios enfrentados pelas mulheres em processos contemporâneos de ascenção profissional. Segundo eles, a sociedade das abelhas apresenta três castas de indivíduos: a rainha, o zangão e as operárias, cujas funções se definem por sua própria natureza e ciclo de vida. A função da rainha é pôr os ovos que darão origem à próxima rainha, aos próximos zangões e a todas as operárias. A abelha rainha possui características importantes e é a base da colmeia, já que é a única fêmea fértil. Caso nasça mais de uma abelha rainha, somente a primeira sobrevive. Aos zangões cabe apenas fecundar a rainha. Tendo cumprido a função, eles vêm a morrer. Já as operárias são as fêmeas estéreis da colméia. A dominação da abelha rainha se dá, portanto, por sua própria natureza.

Desse modo, como na colméia, a vida corporativa apresenta indíviduos do sexo feminino integrados a estruturas dominadas por homens. A expressão "síndrome da abelha rainha" é imputada às mulheres que buscam realização profissional em espaços dominados por homens e que, em lugar de buscar apoio em outras mulheres, distanciam-se delas. Com essa atitude, acabam por se ajustar mais à cultura masculina que à feminina, retroalimentando-a (ARVATEA, GALILEAB e TODESCATC, 2018; DERKS, VAN LAARB e ELLEMERS, 2016).

Para Derks, Van Laarb e Ellemers (2016), dois seriam os motivos de tal comportamento: competição e sobrevivência, afinal, desde a infância, a mulher aprende que deve ser a melhor para conquistar o casamento perfeito, entrando em uma disputa natural com outras figuras femininas. Ao crescer, essa cultura presente em seu subconsciente expõe as mulheres a comportamentos organizacionais de maior competição.

Ainda de acordo com estes autores, o fenômeno da abelha rainha (queenbee) não constitui preconceito de gênero, mas uma forma de sobrevivência, uma resposta à discriminação e à ameaça que tais indivíduos experimentam nos ambientes de trabalho. Segundo eles, as mulheres "[...] acabam por assimilar definições masculinas de liderança à medida que sobem na hierarquia organizacional” (DERKS, VAN LAARB e ELLEMERS, 2016, p. 37). 
O mais intrigante, segundo os autores, é que o comportamento das abelhas rainhas acaba por legitimar a desigualdade de gênero. Na medida em que as próprias mulheres, em vez de agirem com comunalidade e empatia - características tipicamente atribuídas ao feminino -, são críticas em relação às outras mulheres, endossam serem menos ambiciosas e comprometidas que os homens, o que as coloca, por conseguinte, em desvantagem.

A queenbee acredita que conquistou seu espaço de liderança por confiar em si e em seu potencial, que ascendeu profissionalmente por seus próprios esforços e méritos. Logo, qualquer outra mulher também deve passar pelas aflições e lutas pelas quais atravessou e que a configuraram uma profissional de sucesso. Por deter em si características masculinas necessárias para a liderança, não cabe a ela, que venceu, colaborar com as demais.

Tal comportamento não se trata de uma consequência atípica da personalidade feminina, mas surge como resposta à sua inserção em ambientes nos quais o gênero feminino é desvalorizado. Esse argumento ampara-se na teoria da identidade social, que postula que os indivíduos baseiam sua identidade, em parte, no próprio gênero. Ocorre que membros de grupos desvalorizados, ao perceber que as características típicas do seu grupo de origem são consideradas desvalorizadas e não importantes, sentem sua identidade ameaçada (DERKS, VAN LAARB e ELLEMERS, 2016; TAJFEL e TURNER, 1979).

Sendo assim, quanto mais elevado o cargo nas estruturas organizacionais, menos mulheres são encontradas. Concomitantemente, aquelas que alcançam posições de liderança se veem diante de homens que ganham financeiramente mais, do que decorrem duas formas clássicas para se quebrar o paradigma do gênero: agir de modo a elevar o número de representantes no grupo (coletivo) ou trabalhar individualmente para a conquista das posições, comportando-se conforme prescrito pelo paradigma vigente (individual).

Nesse espectro, agir de forma coletiva, como uma mulher dentre outras, sinaliza que todas são tão boas quanto os homens, permitindo maior ênfase às características essencialmente femininas da liderança. Porém elas deparam-se com o temor de atrair os holofotes para as características culturalmente atribuídas às mulheres, como dividir a atenção do trabalho com a família. Utilizar a estratégia do mérito individual, nessa direção, não raro, ventila-se como resposta a tais temores. Ao se colocar como caso isolado que deu certo, a mulher, todavia, afasta-se do seu gênero, juntando-se aos mais fortes.

\section{A mulher na Administração Pública}

Pesquisa do Instituto Brasileiro de Geografia e Estatística - IBGE (2017) aponta, no período 2012-2016, remuneração das mulheres em média $75 \%$, menor que a dos homens. Na mesma pesquisa, apresenta-se como justificativa o menor tempo das mulheres dedicado ao trabalho. No entanto, mesmo se elevando o tempo de dedicação, a diferença permanece. Controlando o diferencial por horas trabalhadas, a razão, em 2016, modifica-se para 86,7\% (IBGE, 2017). No setor público - regra geral os salários são iguais, mas as funções gratificadas são majoritariamente ocupadas por homens.

Ademais, conta-se com menos mulheres no mercado de trabalho, e sua divisão, por sexo, corrobora estudos que indicam a segmentação por gênero: o serviço doméstico remunerado segue como ocupação eminentemente feminina (92,3\%) e a construção civil, como reduto masculino (96\%) (MELO e THOMÉ, 2018). Homens, em geral, direcionam-se para cursos de engenharia e computação, mais bem remunerados no mercado de trabalho, enquanto mulheres, para a área de humanas (SCOTT, 1986). Não obstante a migração para cursos de domínio masculino, a diferenciação salarial persiste (IBGE, 2017).

Ainda de acordo com o IBGE (2017), em média, as mulheres têm rendimentos $24,4 \%$ menor que os dos homens. Além disso, $6,0 \%$ dos homens são empregadores, contra apenas 3,3\% das mulheres; enquanto 3,6\% das mulheres são trabalhadoras familiares, esse percentual cai pela metade $(-1,5 \%)$ em relação ao sexo masculino.

Em 2016, somando-se as horas dedicadas às atividades domiciliares à ocupação profissional propriamente dita, as mulheres trabalharam mais do que os homens, com uma carga horária média que ultrapassa 54 horas semanais; os homens, em média, perfizeram 51,5 horas semanais (IBGE, 2017).

As disparidades salariais são comumente relacionadas à forte ligação entre mulher e família. Trata-se de "interrupções" comuns na carreira da mulher por causa da gravidez e da educação dos filhos; da percepção da sociedade sobre os valores femininos; e da suposta preferência da mulher por um equilíbrio entre vida pessoal e trabalho, o que difere da visão masculina de busca por melhores posições. Essas expectativas, ainda, corroborariam com a cultura da sociedade que define o homem como o provedor e a mulher como cuidadora da prole. 
Percebe-se que tal desigualdade ocupacional e salarial não é praticada somente na esfera privada, mas também na pública. Note-se que nenhuma das cerca de vinte secretarias existentes na Administração Pública Executiva do Estado do Rio de Janeiro, quando da realização desta pesquisa, era dirigida por mulheres, sequer a Secretaria de Estado e Direitos Humanos e Políticas para Mulheres e Idosos.

Sendo assim, pode-se colocar em pauta a pergunta central que orientou a pesquisa, cujos resultados são apresentados neste estudo. Qual o papel de tais metáforas na dinâmica contemporânea do trabalho e da liderança feminina?

\section{METODOLOGIA}

Este estudo caracteriza-se por uma abordagem qualitativa e quantitativa, é composto de entrevistas semiestruturadas e em profundidade, e de aplicação de questões mensuradas por meio de escalas do tipo Likert de cinco pontos.

Para tal foram contatadas $100 \%$ das Subsecretárias atuantes em órgãos da Administração Pública do Rio de Janeiro, tendo o contato sido procedido por meio da técnica da "Bola de Neve", que a despeito de outras técnicas auxilia o alcance a sujeitos de pesquisa de mais difícil acesso, no caso executivas do segundo escalão das instituições alvo do estudo (VOGT, 1999). Como resultado, foi possível entrevistar dez Subsecretárias de Estado, conforme perfil delineado na Tabela 1.

Tabela 1

\section{Perfil das entrevistadas}

\begin{tabular}{|c|c|c|c|c|}
\hline Código & Formação & Setor de atuação & Idade & Estado Civil \\
\hline E01 & Doutorado em Economia & Finanças & 44 anos & Solteira \\
\hline E02 & $\begin{array}{c}\text { Mestrado em Contabilidade e } \\
\text { Finanças }\end{array}$ & Orçamento & 45 anos & Solteira \\
\hline E03 & Contabilidade & Orçamento & 44 anos & Casada com filhos \\
\hline E04 & Pedagogia & Previdência & 63 anos & Divorciada sem filhos \\
\hline E05 & Administração & Transporte & 32 anos & Casada com filhos \\
\hline E06 & Engenharia & Casa Civil & 47 anos & Divorciada com filhos \\
\hline E07 & Pedagogia & $\begin{array}{l}\text { Recursos } \\
\text { Humanos }\end{array}$ & 42 anos & Casada com filhos \\
\hline E08 & Pedagogia & $\begin{array}{l}\text { Recursos } \\
\text { Humanos }\end{array}$ & $\begin{array}{c}\text { Não } \\
\text { informado }\end{array}$ & Divorciada sem filhos \\
\hline E09 & Doutorado em Ciência Política & Tecnologia & 42 anos & Divorciada sem filhos \\
\hline E10 & $\begin{array}{l}\text { Mestrado em } \\
\text { Contabilidade }\end{array}$ & Contabilidade & 32 anos & Casada sem filhos \\
\hline
\end{tabular}

Fonte: Elaborada pelos autores.

Cabe salientar que as entrevistas foram realizadas de forma presencial, com duração média de 45 minutos, totalizando 7 horas de entrevistas e cerca de 240 laudas de transcrição. Os dados transcritos foram então submetidos a tratamento, por meio de análise de conteúdo por categoria (BARDIN, 2011), obtendo-se cinco temas centrais associados a barreiras vivenciadas nas trajetórias ocupacionais das entrevistadas: preconceito; resistências à liderança feminina; estilos de liderança; demandas da vida familiar e investimento em capital social.

As informações obtidas por meio das entrevistas serviram de base para a construção de instrumento qualitativo de coleta de dados - questionário. Por meio da técnica de survey foi possível mensurar quantitativamente as dificuldades associadas à 
ascenção a cargos de liderança de gestoras do segundo escalão (Gerentes) da Secretaria de Planejamento do Rio de Janeiro. Como resultado da aplicação censitária do questionário, foram obtidos 90 questionários, os quais foram, a seguir, submetidos à análise exploratória, envolvendo a verificação de outliers e dados extremos uni e multivariados, resultando numa amostra final de 50 questionários completos e válidos (Tabela 2).

Tabela 2

Perfil das respondentes ao survey

\begin{tabular}{|c|c|c|c|}
\hline Dados Demográficos & Categorias & Frequência & $\%$ \\
\hline \multirow[t]{3}{*}{ Estado Civil } & Solteira & 8 & $16 \%$ \\
\hline & Casada/mora junto & 31 & $62 \%$ \\
\hline & Divorciada/Separada/Viúva & 11 & $22 \%$ \\
\hline \multirow[t]{2}{*}{ Filhos } & $\operatorname{Sim}$ & 27 & $54 \%$ \\
\hline & Não & 23 & $46 \%$ \\
\hline \multirow[t]{4}{*}{ Escolaridade } & Ensino Fundamental & 1 & $2 \%$ \\
\hline & Graduação & 10 & $20 \%$ \\
\hline & Mestrado/Doutorado & 11 & $22 \%$ \\
\hline & Pós graduação/Especialização/MBA & 28 & $56 \%$ \\
\hline
\end{tabular}

Fonte: Elaborada pelos autores.

Com base nos itens do questionário, desenvolvido por meio das categorias identificadas na etapa qualitativa do estudo, algumas hipóteses puderam ser estabelecidas à luz da teoria revisada para fins deste estudo.

Hipótese 1: Quanto maior a feminilidade (masculinidade/ masculino), maior a comunalidade (agência) e a identidade feminina (masculina).

Hipótese 2: Quanto mais agênticas/masculinas, menor o vestígio de preconceito (maior a negação da discriminação).

Hipótese 3: Quanto mais agênticas/masculinas, menor a resignação (menor a resistência).

Hipótese 4: Quanto mais agênticas/masculinas, maior a resiliência na carreira de gestão.

Hipótese 5: Quanto mais agênticas/masculinas, maior a aceitação na carreira de gestão.

Hipótese 6: Quanto mais agênticas/masculinas, maior distanciamento; e menor disposição para apoiar outras mulheres.

Hipótese 7: Quanto mais agênticas/masculinas, maior o comprometimento com a carreira.

\section{ACHADOS E DISCUSSÃO}

\section{Barreiras à ascenção e exercício da liderança segundo lideranças públicas femininas entrevistadas}

Acerca de preconceitos vivenciados nos ambientes de trabalhos decorrentes da condição de mulheres, a maioria das entrevistadas (06) indica, inicialmente, não terem sido objeto de preconceitos. Paradoxalmente, quando perguntadas sobre a existência de preconceitos sofridos por outras mulheres, a totalidade salienta acreditar em sua existência. Importante destacar relatos que sugerem ou apontam fatos que se enquadrariam em situações de preconceito, mas que foram, todavia, ignorados pelas entrevistadas.

Pode-se inferir que, ao não evidenciar formas de preconceito, as entrevistadas parecem evitar algum tipo de questionamento ao sucesso alcançado. Em outros termos, parecem querer enfatizar que os motivos que as fizeram ascender ligam-se eminentemente a "fatores objetivos", suas competências e capacidade, independemente do sexo, de alcançar posições em 
condições de igualdade e mérito com os homens. Ou seja, o preconceito parece mais associado a construções conscientes ou inconscientes de "fragilidade" da posição da mulher na dinâmica organizacional que a aspectos estruturais ou culturais:

Não, nenhuma discriminação. Eu acho que tem que estar certo do cargo. Não adianta você aceitar um cargo desse e não achar que sua vida vai mudar, porque vai (E03).

Não, não vejo preconceito [...] antes de assumir o cargo, eu fui sondada para saber sobre o meu futuro, se pretendia ter filhos, essas coisas (E10).

Outros relatos, por sua vez, apontam para a existência de preconceitos, sendo sintomática a carência de mulheres em cargos da alta administração. Mesmo concursadas e, não raro, mais escolarizadas, há poucas mulheres em posições estratégicas e politicamente relevantes. Associado a isso, apontam para "[...] a falta de respeito no que se refere ao modo de liderar da mulher, rotuladas de "histéricas ou neuróticas'". Outras barreiras relacionam-se a estratégias de polarização das ocupações, cabendo às mulheres áreas e posições menos valorizadas (SUSSKIND e SUSSKIND, 2017):

Por que que a mulher só pode ser da Subsecretaria da Mulher? Ou vinculada a uma área de educação ou a algo relacionado à mulher e se for negra tem que obrigatoriamente ser da igualdade racial? (E01).

Eagly e Carli (2007) apontam para a existência de um conjunto de crenças sobre as características femininas e masculinas de exercício da liderança que tornam diferentes homens e mulheres. As mulheres são comumente consideradas comunais e os homens agênticos, como sinônimo de bom líder, por suas características de pró-atividade, dinamismo, pragmatismo e ênfase em resultados. Ignora-se, portanto, a possibilidade de existência de mulheres não comunais ou andrógenas, ou seja, feminina em sua fisionomia, mas com traços masculinos de liderança e gestão. Quanto agênticas, quanto andrôgenas, as líderes, descritas por Eagly e Carli (2007), como em "duplo vínculo", escapam à regra, e se veem comumente estigmatizadas:

[...] a minha equipe demorou para se acostumar comigo, com o meu jeito de lidar. Reclamaram porque eu cheguei cheia de marra, quando na verdade eu queria era ver trabalho (E1).

[...] e eu acho que o maior desafio foi eu ter saído do setor $\mathrm{x}$ e ter ido para a área comercial, porque este não foi um desafio única e exclusivamente profissional, foi de postura. Eu tive que sair de uma posição respectiva para uma posição agressiva, que é de ir ao mercado buscar negócios (E4).

Sobre as características relevantes ao crescimento profissional e aos desafios e barreiras à ascenção das mulheres a posições de maior responsabilidade e liderança, uma vez mais a cultura agêntica é caracterizada como como a liderança adequada , o que leva muitas mulheres a se comportarem segundo esse padrão. Destacam, ainda, serem tais comportamentos difundidos tanto de forma sutil quanto pelos dispositivos internos de desenvolvimento e avaliação de desempenho. Como resultados,

[...] não tenho dúvidas de que ser pragmática é uma característica boa a quem busca o exercício da liderança em posições mais estratégicas. Todas nós que chegamos até aqui possuímos essa característica (E5).

Coerentemente com a teoria que tende a denotar a existência de estilos de liderança mais fortes - masculinos -, a maioria das entrevistadas tende a reproduzi-los. Provavelmente para afirmarem seu poder e autoridade, parecem assumir traços de assertividade, em particular diante de cobranças por resultados. Aliás, características típicas associadas ao exercício e legitimação da liderança revelaram-se bastante similares: assertividade, pragmatismo, impessoalidade. Somente duas entrevistadas indicaram perfis mais agregadores:

Eu sou um trator. A minha maneira de ser é porque eu acredito tanto que a pessoa tem capacidade de fazer que eu não admito nada ser realizado (E09).

Quando virei chefe de gabinete, só tinha homem e incomoda aos homens e às mulheres. No dia da mulher somos lembradas e passou o dia e acabou (E06).

As entrevistas trazem também à tona relações "mulher-trabalho-família". Por fatores culturais, o aspecto familiar é comumente apontado como de peso significativo em tal triangulação. Os estudos de Eagly e Carli (2007) revelam que as mulheres tendem a trabalhar menos horas para dar conta da família e são mais propensas a deixar suas carreiras, caso tenham de decidir entre um e outro caminho. Contudo, contrariamente ao observado pelas autoras, os relatos das entrevistadas no presente estudo 
não indicam problemas nesse quesito. É possível que o tipo de instituição - setor público - tenha características específicas que minimizam estes impactos sobre as profissionais, comparativamente às instituições do setor privado:

Não, não me prejudicou ter filhos, mas me cansava mais. Mas eu dava conta. Até que meu primeiro marido falou: o curso ou eu? Eu escolhi o curso e aí as coisas foram se clareando e nós nos separamos (E06).

Embora a sociedade, em geral, ainda entenda que quem deve cuidar da família e, principalmente, dos filhos, sejam as mães, para as profissionais esta visão já se encontra superada. Contrariamente ao traço cultural, elas apontam ter vontades e ambições profissionais, mas buscam alinhá-los ao desejo de constituir família. Para elas, trata-se mais de encontrar um parceiro que respeite tal decisão, e menos de fatores organizacionais propriamente ditos:

É fundamental (ter família). E eu acho que a mulher pode ter tudo. Ela pode constituir família e ter sucesso profissional. É questão de dividir tarefas. Não é só a mulher que é a responsável pela família, só a mulher tem que estar disponível, isso leva a relação a um processo de fracasso (E01).

Salietam, também, não terem alterado sua carga de trabalho. Segundo elas, no entanto, o apoio familiar revelou-se fundamental, quer na compreensão das ausências, quer no apoio às atividades domésticas e maternas:

Minha vida lá fora é normal. Acordo cedo, faço café da manhã, cuido do meu filho e marido. Se estou numa festa e o telefone toca, saio e atendo. Eles entendem a minha posição, não tenho problema nenhum quanto a isso. Minha família me apoia e apesar de cansativo, é o que eu gosto de fazer (E07).

Ademais, elas apontam que cuidar da família e, concomitantemente, ocupar posição de liderança acabam por comprovar e legitimar, pelo enfrentamento dos desafios inerentes ao duplo papel, sua efetiva capacidade:

Eu tenho um filho pequeno de um ano. Engravidei ainda no cargo, tirei licença e voltei. Isso não mudou. Muito pelo contrário, trabalho mais para provar que posso manter os dois. Meu marido ajuda e tem dado certo. Somos uma família e tem dado certo (E09).

As entrevistadas solteiras ou divorciadas afirmam tratar-se de questão de escolha entre a profissão ou o companheiro, levando a crer que alcançar o alto escalão pressupõe a decisão de abrir mão de construírem uma família ou investirem em relações afetivas

No meu divórcio, o que pesou para eu me separar foi o fato do meu marido não ter um pensamento de crescimento. Um homem inteligente e disputado, mas que dava mais valor a outras coisas que não eram o trabalho. E eu queria crescer profissionalmente, e a gente começou a entrar em choque com isso (E04).

No entanto, para várias entrevistadas, possuir um porto seguro faz diferença, seja com a família - filhos ou marido - a mãe, ou até mesmo um profissional terapeuta. Foi unânime a importância ao bem-estar pessoal para que a vida profissional possa fluir, mesmo que signifique:

Seguir sozinha, sem um companheiro. Você precisa ter um apoio emocional, um terapeuta não vai te dar este apoio. Você realmente precisa, quando abre mão de determinadas áreas da sua vida [...]. Ou seja, você precisa sim, ter um apoio, seja da mãe, do marido, mas precisa ter um aconchego (E01).

Nesse estágio das entrevistas, comumente esbarra-se na definição do que seria ser mãe, ter família, o que para cada pessoa pode ter um sentido específico. Uma das entrevistadas, todavia, traz à luz uma questão relevante, a qual merece maiores considerações:

Eu não sou uma mãe comum. [...] Minha filha, por exemplo, eu luto como mãe de outra forma, sou presidente do Conselho Municipal da escola dela e ela tem mó orgulho. Eu não sou uma mãe comum, mas quem é, atualmente? Não dá para ter estereótipo. Eu me questiono mais de outra coisa. [...] Talvez eu não lembre de cortar o cabelo dela todos os meses, mas a minha forma de ser mãe é essa, zelar pelo futuro dessa forma. E ela acha isso o máximo (E05).

O tema família é, desse modo, apontado como "problemático", impedimento ao crescimento profissional (glass ceiling). Para elas, todavia, as maiores pressões não se limitam ao ambiente organizacional, advindo também do contexto familiar. 
Conforme as entrevistadas, as famílias muitas vezes não entendem o porquê da opção pela carreira pofissional em detrimento da maternidade, opção que, quase sempre, as coloca na posição de mulheres faltosas, incompletas":

Eu sofro discriminação de ter escolhido não ser mãe, mais lá fora (de amigos) do que no trabalho. Pessoas que não fariam o que eu fiz, a maior parte das minhas amigas preferem não trabalhar, reduzir custo de vida e engravidar e ter filhos. Elas acham que eu devia largar tudo, tirar licença e cuidar do filho, porque o tempo passa e a criança vai sofrer, o tempo vai correr, te culpam antes de ter filho. Você não pode ter filho porque não vai dar atenção, mas o que é criar direito? Eu conheço pessoas que são mães que ficam em casa e não dão a menor atenção aos filhos e as mães que trabalham e dão muito mais atenção aos filhos (E10).

Além da categoria relações família-trabalho, os investimentos em capital social, em particular a construção de networkings e laços sociais e profissionais de contato, são apontados pela literatura como importantes elementos para o crescimento profissional em qualquer área. Recente estudo, desenvolvido por Lee, Marshall, Rallis et al. (2018), sugere que o capital social é ainda mais necessário para o avanço dos gerentes que o desempenho de habilidades gerenciais tradicionais. Contudo muitas mulheres se ressentem por não conseguir mobilizar tão bem este lado quanto os homens, constituindo fator de limitação aos seus anseios de ascenção profissional:

Acho que deveríamos ter mais disponibilidade, porque para você disputar, você precisa estar disponível o tempo inteiro. Chegar em casa tarde e ninguém ter morrido de fome, ninguém estar te esperando. As coisas estão acontecendo. Acho que a gente precisa se esforçar mais por conta disso: mais organizada, mais disciplinada, tentar saber a matéria a fundo para poder diminuir um pouco o tempo que o cara fica pensando e fazer mais rápido para ter o mesmo resultado (E03).

Características da líderança feminina emergem também como uma categoria analítica relevante. As dez Subsecretárias entrevistadas apresentam tons de voz e posicionamentos muito parecidos, procurando evidenciar assertividade e objetividade. Diante de tais comportamentos, ao serem questionadas sobre traços ou características que as mulheres comumente manifestam quando em posições profissionais de liderança, a grande maioria faz menção ao domínio e conhecimento técnico, algo primordial para elas. De acordo com os relatos, a preocupação em ser melhor que o sexo oposto, apesar de velada, encontra-se presente. Comportamentos mais delicados, de compaixão ou emoção, segundo elas, geralmente as expõem ao risco de serem tachadas como "lideranças fracas".

Nesse contexto, a "síndrome da abelha rainha" manifesta-se nos relatos como características de liderança frente a outras mulheres, em especial com subordinadas:

A mulher não acredita nela mesmo e tem discriminção entre elas. O homem é criado para ser cuidado, a mulher é criada para cuidar do outro (E04).

Ainda em relação à colaboração com outras pessoas do mesmo sexo, três entrevistadas relatam que seus mentores, ou pessoas que de certa forma colaboram para o seu processo de desenvolvimento profissional, são homens:

Quando eu entrei no Estado, tinha um rapaz que fazia este trabalho, e como era muito chato, eu entrei novinha, ele começou a me ensinar esta parte orçamentaria. É uma dificuldade, porque tem um montão de coisas específicas da administração pública (E03).

Para as entrevistadas há uma dificuldade de aproximação entre as mulheres hierarquicamente superiores e as outras. Acreditam, no entanto, que suas subordinadas podem crescer profissionalmente, basta para tal, decidirem entre o trabalho e a família". Em outros termos, estarem "dispostas a pagar o preço":

Eu acho que amulher pode muitas vezes se destacar, mas acho que ao logo da vida tem essa questão da mulher decidir entre a vida profissional e a maternidade. Apenas após essa decisão, a mulher poderá lutar pelo seu espaço como líder (E06).

Em suma, os relatos obtidos permitiram identificar e categorizar as principais barreiras apontadas pelas lideranças públicas femininas entrevistadas em cinco grandes temas: preconceito; resistências à liderança feminina; estilos de liderança; demandas da vida familiar e investimento em capital social. Conforme a metodologia aplicada, tais categorias e seus respectivos 
indicadores serviram de base para a elaboração do questionário posteriormente aplicado às gestoras atuantes no setor público. Os resultados do survey são apresentados no tópico a seguir.

\section{Barreiras à liderança feminina segundo gestoras públicas alvo do survey}

Na Tabela 3 são reportadas estatísticas descritivas de fatores sóciodemográficos e profissionais das respondentes ao survey, bem como das categorias investigadas com gestoras ocupantes de posições gerenciais de segundo escalão da instituição pública alvo da pesquisa. Cabe salientar que as categorias investigadas decorrem de etapa preliminar de entrevistas com Subsecretárias de Estado.

Tabela 3

Dados quantitativos: Gestoras do segundo escalão de Secretarias de Estado

\begin{tabular}{l|c|c|c|c}
\hline & Média & Desvio Padrão & Mínimo & Máximo \\
\hline Idade & 39,41 & 8,44 & 10 & 55 \\
\hline Experiência & 16,87 & 7,41 & 1 & 30 \\
\hline Tempo na Área Pública & 10,29 & 7,09 & 0 & 20 \\
\hline Tempo de Gestão & 4,79 & 4,07 & 0 & 43 \\
\hline No de Subordinados & 7,81 & 9,98 & 0 & 16 \\
\hline No deSubordinadas Mulheres & 4,02 & 4,32 & 2,6 & 5 \\
\hline Feminilidade & 4,11 & 0,63 & 2,5 & 5 \\
\hline Masculinidade & 3,86 & 0,59 & 4,3 & 7 \\
\hline Comunalidade & 6,12 & 0,62 & 3 & 5 \\
\hline Identidade de Gênero & 4,03 & 0,46 & 4,5 & 7 \\
\hline Agência & 5,87 & 0,74 & 2,3 & 7 \\
\hline Negação da Discriminação & 4,38 & 1,16 & 1,3 & 7 \\
\hline Resignação & 4,46 & 1,58 & 3,3 & 7 \\
\hline Resiliência & 6,12 & 0,85 & 2 & 6,6 \\
\hline Aceitação & 5,13 & 1,16 & 1,3 & 5 \\
\hline Distanciamento & 2,63 & 1,1 & 1 & 7 \\
\hline Disposoção & 3,79 & 1,06 & & 6 \\
\hline Comprometimento & 3,56 & 1,12 & & \\
\hline
\end{tabular}

Nota: Todas as variáveis latentes, i.e., as variáveis criadas a partir de um conjunto de perguntas aplicadas no questionário foram obtidas através da média das respostas de cada um dos itens. Por exemplo, o construto "Feminilidade" é composto por 10 perguntas previamente selecionadas na Literatura específica e os valores aqui reportados leva em consideração a média destes 10 valores reportados em escala Likert. Raciocínio análogo é válido para as variáveis Masculinidade, Comunalidade, Identidade de Gênero, Agência, Negação da Discriminação, Resignação, Aceitação, Distanciamento e Comprometimento.

Fonte: Elaborada pelos autores.

A Tabela 4, por sua vez, dispõe resultados da matriz de correlação entre as categorias investigadas. Como resultado, registra-se forte associação positiva entre idade e anos de experiência $(\rho=.776)$, entre experiência profissional e tempo de serviço na instância pública $(\rho=.589)$, bem como entre tempo de gestão e tempo de serviço na área pública $(\rho=.666)$. Entre as variáveis latentes, cabe ressaltar a correlação positiva e significante entre masculinidade e líderes agentes $(\rho=.641)$, masculinidade e disposição ( $\rho=.651)$, masculinidade e comprometimento $(\rho=.722)$, disposição e líderes agentes $(\rho=.675)$, comprometimento e disposição $(\rho=.711)$.

Apesar de as correlações apresentarem-se em linha com a teoria e as hipóteses propostas, faz-se necessária uma análise mais pormenorizada dos achados, o que será realizado mais adiante. 
Tabela 4

Matriz de Correlações

\begin{tabular}{|c|c|c|c|c|c|c|c|c|c|c|c|c|c|c|c|c|c|}
\hline & & (1) & (2) & (3) & (4) & (5) & (6) & (7) & (8) & (9) & (10) & (11) & (12) & (13) & (14) & (15) & (16) \\
\hline$(1)$ & Idade & 1.0000 & & & & & & & & & & & & & & & \\
\hline$(2)$ & Experiência & $0.7776^{*}$ & 1.0000 & & & & & & & & & & & & & & \\
\hline (3) & $\begin{array}{l}\text { Tempo na Área } \\
\text { Pública }\end{array}$ & 0.3925 & $0.5894^{*}$ & 1.0000 & & & & & & & & & & & & & \\
\hline (4) & Tempo de Gestão & 0.3113 & 0.3743 & $0.6662^{*}$ & 1.0000 & & & & & & & & & & & & \\
\hline (5) & Feminilidade & -0.0475 & 0.0462 & 0.1014 & -0.3160 & 1.0000 & & & & & & & & & & & \\
\hline (6) & Masculinidade & 0.0202 & 0.2123 & 0.0509 & -0.1266 & $0.4709 *$ & 1.0000 & & & & & & & & & & \\
\hline (7) & Comunalidade & -0.0338 & -0.1704 & -0.1972 & -0.3219 & $0.4853^{*}$ & 0.2668 & 1.0000 & & & & & & & & & \\
\hline (8) & $\begin{array}{l}\text { Identidade de } \\
\text { Gênero }\end{array}$ & -0.2485 & -0.2177 & -0.0276 & -0.1724 & $0.5500^{*}$ & $0.3559 *$ & $0.3637^{*}$ & 1.0000 & & & & & & & & \\
\hline (9) & Agência & 0.0323 & 0.0451 & -0.0580 & -0.1398 & 0.5439* & $0.6419 *$ & $0.5503 *$ & $0.4323 *$ & 1.0000 & & & & & & & \\
\hline (10) & $\begin{array}{l}\text { Negação da } \\
\text { Discriminação }\end{array}$ & -0.2789 & -0.2259 & 0.0041 & -0.4228 & 0.3463 & $0.3888^{*}$ & 0.2326 & 0.3261 & $0.5444^{*}$ & 1.0000 & & & & & & \\
\hline (11) & Resignação & -0.0279 & -0.0972 & -0.0697 & -0.1959 & 0.1866 & 0.2055 & 0.2768 & 0.3527 & 0.3579* & $0.4791^{*}$ & 1.0000 & & & & & \\
\hline (12) & Resiliência & -0.1741 & -0.0582 & 0.0562 & -0.1893 & 0.1415 & 0.1809 & 0.2257 & 0.2505 & 0.1154 & 0.2754 & 0.1619 & 1.0000 & & & & \\
\hline (13) & Aceitação & -0.2642 & -0.0788 & 0.0225 & -0.0626 & 0.1165 & -0.0055 & 0.0397 & 0.2682 & 0.2535 & 0.2123 & -0.1866 & 0.2668 & 1.0000 & & & \\
\hline (14) & Distanciamento & -0.1528 & -0.0535 & -0.1804 & -0.1734 & 0.2909 & $0.4729 *$ & 0.2357 & 0.2389 & 0.2500 & $0.4254^{*}$ & 0.3558 & 0.0945 & -0.1054 & 1.0000 & & \\
\hline (15) & Disposoção & 0.1467 & 0.1204 & 0.0004 & 0.0086 & 0.3004 & $0.6518^{*}$ & $0.4790^{*}$ & 0.3084 & $0.6753 *$ & 0.3451 & 0.3146 & 0.2114 & 0.0745 & 0.2440 & 1.0000 & \\
\hline (16) & Comprometimento & 0.2164 & 0.1504 & 0.1340 & -0.0391 & 0.2604 & $0.7223^{*}$ & 0.3153 & 0.2934 & $0.5676^{*}$ & 0.3545 & 0.2479 & 0.2465 & 0.0461 & 0.2366 & $0.7113^{*}$ & 1.0000 \\
\hline
\end{tabular}

Nota: *indica significância ao nivel de $1 \%$.

Fonte: Elaborada pelos autores.

Tendo por base o teste das hipóteses propostas, foi possível corroborar a hipótese 1 (H1), verificando-se, conforme disposto na Tabela 5, comunalidade entre liderança e feminilidade $(\beta=.4126, p<.01)$; isto é, quanto maior o grau de feminilidade, maior a identificação com seu gênero $(\beta=.4079, p<.01)$. A hipótese pode ser validada também no que se refere à masculinidade: as lideranças com este traço mais latente tendem a ser mais agênticas $(\beta=.6912, p<.01)$, apesar de não perderem a identificação com o gênero feminino $(\beta=.2828, p<.01)$, mas o perceberem com menor intensidade $\left(\beta_{\text {masc }}=.2828<\beta_{\text {femin }}=.4079\right)$. Cabe ressaltar, além disso, o alto poder explanatório do modelo, apesar da amostra restrita a cinquenta gestoras.

Tabela 5

Teste H1

\begin{tabular}{c|c|c|c|c}
\hline & Communalidade & Id Gênero & Agência & Id Gênero \\
\hline Feminilidade & $\begin{array}{c}0.4126^{* * *} \\
(0.1072)\end{array}$ & $\begin{array}{c}0.4079 * * * \\
(0.0867)\end{array}$ & - \\
\hline Masculinidade & - & - & $0.6912^{* * *}$ & $0.2828^{* * *}$ \\
& & & $(0.1191)$ & $(0.1040)$ \\
\hline Constante & $4.3921^{* * *}$ & $2.3566^{* * *}$ & $3.1545^{* * *}$ & $2.9403^{* * *}$ \\
& $(0.4422)$ & $(0.3609)$ & $(0.4645)$ & $(0.4068)$ \\
\hline Observações & 50 & 53 & 50 & 53 \\
\hline R-Quadrado & 0.2356 & 0.3025 & 0.4120 & 0.1267 \\
\hline
\end{tabular}

Nota: Os erros-padrão estão reportados entre parênteses e *** indicam significância ao nível de $1 \%$. Fonte: Elaborada pelos autores.

Com o intuito de testarmos a segunda hipótese (H2), percebemos abaixo (Tabela 6) que a hipótese foi parcialmente suportada, uma vez que quanto maior a agência, maior o preconceito reportado $(\beta=.5708, p<.01)$; ao passo que quanto maior a masculinidade, também maior a negação da discriminação $(\beta=.7638, p<.01)$. Comparativamente aos modelos da primeira hipótese, constata-se a redução do poder explanatório (R-quadrado). 
Tabela 6

Teste $\mathrm{H} 2$

\begin{tabular}{l|c|c}
\hline Agência & $\begin{array}{c}\text { Vestígio de Preconceito } \\
\text { Masculinidade }\end{array}$ & $\begin{array}{c}\text { Negação da Discriminação } \\
(0.1459)\end{array}$ \\
\hline Constante & - & $\begin{array}{c}0.7638^{* * *} \\
(0.2534)\end{array}$ \\
\hline Observações & 1.1882 & 1.4353 \\
$(0.8386)$ & $(0.9915)$ \\
\hline R-Quadrado & 46 & 53 \\
\hline
\end{tabular}

Nota: Os erros-padrão estão reportados entre parênteses e

*** indicam significância ao nível de $1 \%$.

Fonte: Elaborada pelos autores

Com relação à $H 3$, que visa compreender em que medida a liderança agêntica, incorporadora do papel social masculino, explica a menor resignação e resistência feminina (Tabela 7), os resultados não permitem suportar a hipótese, obtendo-se relação negativa entre as variáveis. Em outros termos, ao mesmo passo que a liderança agêntica relaciona-se com maior resignação $(\beta=.7656, p<.01)$, o efeito da masculinidade não é significativamente diferente de zero $(\beta=.5609, p>.10)-$ o que pode ser explicado pelo baixo poder explanatório do modelo $\left(R^{2}=.04\right)$.

\section{Tabela 7}

Teste H3

\begin{tabular}{l|c|c}
\hline Agência & Resignação & Resignação \\
\hline Masculinidade & $\begin{array}{c}0.7656^{* * *} \\
(0.2853)\end{array}$ & - \\
\hline Constante & - & $\begin{array}{c}0.5609 \\
(0.3855)\end{array}$ \\
\hline Observações & 5.0370 & $\begin{array}{c}2.2504 \\
(1.5026)\end{array}$ \\
\hline R-Quadrado & 0.1281 & 50 \\
\hline
\end{tabular}

Nota: Os erros-padrão estão reportados entre parênteses e *** indicam significância ao nível de $1 \%$.

Fonte: Elaborada pelos autores

Já no que se refere às hipóteses $\mathrm{H} 4$ e $\mathrm{H} 5$, também não se pode afirmar que a liderança mais agêntica e masculina apresenta maiores índices de resiliência ( $\beta=.1837$ e $\beta=.3026, p>.10$, respectivamente) ou aceitação de suas carreiras ( $\beta=.5545$ e $\beta=$ -.0127, p > .10, respectivamente). Tal como em relação à H3, é possível que a não significância decorra dos baixos poderes explanatórios dos modelos referenciados, inferiores a 6\% (Tabela 8). 
Tabela 8

Testes H4 e H5

\begin{tabular}{l|c|c|c|c}
\hline Agência & Resiliência & Resiliência & Aceitação & Aceitação \\
\hline Masculinidade & $\begin{array}{c}0.1837 \\
(0.2383)\end{array}$ & - & $\begin{array}{c}0.5545 \\
(0.3190)\end{array}$ & - \\
\hline Constante & - & $\begin{array}{c}0.3026 \\
(0.2480)\end{array}$ & - & $\begin{array}{c}-0.0127 \\
(0.3466)\end{array}$ \\
\hline Observações & $\begin{array}{c}5.0719 * * * \\
(1.3694)\end{array}$ & $\begin{array}{c}4.9756 * * * \\
(0.9488)\end{array}$ & $\begin{array}{c}1.9578 \\
(1.8330)\end{array}$ & $\begin{array}{c}5.1786 * * \\
(1.3259)\end{array}$ \\
\hline R-Quadrado & 0.0133 & 46 & 46 & 46 \\
\hline
\end{tabular}

Nota: Os erros-padrão estão reportados entre parênteses e *** indicam significância ao nível de $1 \%$.

Fonte: Elaborada pelos autores

No que tange, por sua vez, à hipótese $\mathrm{H6}$, seria de se esperar que lideranças mais agênticas e masculinas estivessem relacionadas a maior distanciamento em relação a suas equipes e a menor disposição para apoiar outras mulheres. Os achados, no entanto, revelam suporte parcial das hipóteses. De modo geral, tanto as lideranças agênticas femininas quanto as masculinas mantêm maior distanciamento em relação a suas equipes $\left(\beta_{\text {agência }}=.3746, p<.10 ; \beta_{\text {masculinidade }}=.9190, p<.01\right)$, bem como maior disposição para apoiá-las quando for necessário $\left(\beta_{\text {agência }}=.9750, p<.10 ; \beta_{\text {masculinidade }}=1.1142, p<.01\right)$.

Tabela 9

Teste H6

\begin{tabular}{l|c|c|c|c}
\hline Agência & Distanciamento & Distanciamento & Disposição & Disposição \\
\hline Masculinidade & $\begin{array}{c}0.3746^{*} \\
(0.2073)\end{array}$ & - & $\begin{array}{c}0.9750^{* * *} \\
(0.1521)\end{array}$ & - \\
\hline Constante & 0.4346 & $\begin{array}{c}0.9190^{* * *} \\
(0.2471)\end{array}$ & - & $\begin{array}{c}1.1142^{* * *} \\
(0.1871)\end{array}$ \\
\hline Observações & $(1.2282)$ & $(0.9632)$ & $\begin{array}{c}-1.9416^{* *} \\
(0.9012)\end{array}$ & $\begin{array}{c}-0.5700 \\
(0.7293)\end{array}$ \\
\hline R-Quadrado & 0.0625 & 0.2236 & 0.4561 & 0.4248 \\
\hline
\end{tabular}

Nota: Os erros-padrão estão reportados entre parênteses $e^{*}, * * \mathrm{e}^{* * *}$ indicam significância ao nível de $10 \%$, 5\% e $1 \%$.

Fonte: Elaborada pelos autores.

Finalmente os dados da Tabela 10 apresentam os resultados do teste da H7. Pelos resultados, tanto masculinidade quanto agência apresentam-se positiva e significativamente relacionadas com comprometimento com a carreira ( $\beta_{\text {agência }}=.8606$, $\left.\mathrm{p}<.01 ; \beta_{\text {masculinidade }}=1.3650, \mathrm{p}<.01\right)$. Os $\mathrm{R}^{2}\left(\mathrm{R}_{\text {agência }}=.3221\right.$ e $\left.\mathrm{R}_{\text {masculinidade }}^{2}=.5218\right)$, no entanto, indicam que quanto mais agênticas ou masculinas as gestoras, maior seu comprometimento no trabalho. 


\section{Tabela 10}

\section{Teste $\mathrm{H7}$}

\begin{tabular}{|c|c|c|}
\hline & Commitment & Commitment \\
\hline Agência & $\begin{array}{c}0.8606 * * * \\
(0.1783)\end{array}$ & - \\
\hline Masculinidade & - & $\begin{array}{c}1.3650 * * * \\
(0.1886)\end{array}$ \\
\hline Constante & $\begin{array}{l}-1.4980 \\
(1.0567)\end{array}$ & $\begin{array}{c}-1.7501^{* *} \\
(0.7351)\end{array}$ \\
\hline Observações & 51 & 50 \\
\hline R-Quadrado & 0.3221 & 0.5218 \\
\hline
\end{tabular}

Nota: Os erros-padrão estão reportados entre parênteses $e^{*}, * * \mathrm{e}^{* * *}$ indicam significância ao nível de $10 \%$, 5\% e $1 \%$.

Fonte: Elaborada pelos autores.

Isto posto, o Quadro 1 sintetiza os resultados dos testes para o conjunto das hipóteses investigadas.

\section{Quadro 1}

\section{Testes de Hipóteses: Resumo}

\begin{tabular}{|c|l|c|}
\hline Hipotéses & \multicolumn{1}{|c|}{ Descrição } & Suporte \\
\hline H1 & $\begin{array}{l}\text { Quanto maior a feminilidade (masculinidade/masculino), maior a comunalidade } \\
\text { (agência) e a identidade feminina (masculina). }\end{array}$ & Sim \\
\hline H2 & $\begin{array}{l}\text { Quanto mais agênticas/masculinas, menor o vestígio de preconceito (maior a negação } \\
\text { da discriminação). }\end{array}$ & Parcial \\
\hline H3 & Quanto mais agênticas/masculinas, menor a resignação (menor a resistência). & Parcial \\
\hline H4 & Quanto mais agênticas/masculinas, maior a resiliência na carreira de gestão. & Não \\
\hline H5 & Quanto mais agênticas/masculinas, maior a aceitação na carreira de gestão. & Não \\
\hline H6 & $\begin{array}{l}\text { Quanto mais agênticas/masculinas, maior a) distanciamento; e menor b) disposição } \\
\text { para ajudar outras mulheres. }\end{array}$ & Parcial \\
\hline H7 & Quanto mais agênticas/masculinas, maior o comprometimento com a carreira. & Sim \\
\hline
\end{tabular}

Fonte: Dados da pesquisa.

\section{CONCLUSÕES}

Com base no conjunto dos dados obtidos, pode-se constatar que a mulher ainda sofre preconceitos validados por códigos masculinos em sua busca por ascensão a posições de maior responsabilidade e liderança, requerendo que tenham de provar com mais frequência e intensidade sua competência profissional.

A noção de "essencialismo genérico", que vincula o preconceito à natureza biológica homem-mulher, ainda se coloca como fator de legitimação das barreiras à ascenção profissional feminina. Nesse caso, pode-se dizer que a transmutação de tal visão requer tempo, luta e desejo.

A realização da mulher, antes restrita à esfera familiar, cada vez mais se dá na esfera do trabalho. Acrescenta-se a isto, a busca de independência financeira que propicia à mulher superar a posição de dependência e subordinação masculina. A independência financeira confere à mulher liberdade, bem como sentido de propriedade de sua existência. Liberdade que, todavia, não afasta as mulheres do desejo de constituir uma família. Ao contrário, permite que ela escolha a forma de família que melhor convêm ao seu desejo. 
Atualmente, ao buscar ocupar posições mais estratégicas nas organizações, além de maior escolaridade e competência técnica, as mulheres veem-se diante do desafio de compensar os estereótipos de fragilidade e as barreiras à ascenção, tangíveis e intangíveis. Ao resistir aos paradigmas hegemônicos de liderança e gestão, incorporando políticas e práticas mais humanas e empáticas, todavia, dão espaço a revoluções comportamentais almejadas pela sociedade contemporânea, aportando novos sentidos ao trabalho, à gestão e à liderança.

Não obstante, a mulher ainda encontra-se em ambiente desfavorável, o qual ignora seu potencial de superação de modelos de negócios e organizacionais já esgotados. Selecionar um profissional unicamente por conta de seu gênero, etnia ou religião consiste em atitude preconceituosa. Não se pode ignorar que a diversidade constitui valor e fator irrefutáveis de inovação, criação e humanização dos espaços de convivência e trabalho. A mudança de mentalidade, igualmente, não pode limitar-se à imposição da lei, pelo contrário, deve avançar por meio da difusão de valores e da educação.

Efetuar mudanças dessa magnitude não constitui tarefa simples, mas possível de ser realizada com vontade e políticas inclusivas. No caso deste estudo, os dados sugerem que as mulheres quando percebem que outras, como elas, vivenciam suas mesmas dificuldades e desafios, podem sentir-se mais engajadas e conscientes de suas particularidades e possibilidades comuns.

Reconhece-se que uma agenda para a mudança, inspirada em valores mais solidários que competitivos, seja relevante na construção de uma cidadania mais inclusiva e participativa. Consequentemente, também são construídas instituições aptas a mediar e regular as relações indivíduo-trabalho-organizações-sociedade que caracterizam, em particular, a transição para a chamada "Economia Digital" ou "Quarta Revolução Industrial", cujas mutações nas estruturas e dinâmicas societais e organizacionais se evidenciam sem precedentes (SCHWAB, 2016). Dados apontam, por exemplo, os riscos de intensificação do fenômeno de polarização das profissões. Haja vista reduzido número de mulheres em cursos e áreas como tecnologia, mecatrônica, pesquisa, desenvolvimento e inovação, conquistas obtidas podem, na próxima geração, retroceder, considerando que nestas áreas estarão as ocupações mais valorizadas do mercado de trabalho (SANT'ANNA e MELLO, 2018; SUSSKIND e SUSSKIND, 2017).

As mulheres tiveram papel decisivo nas transformações políticas, sociais, econômicas e comportamentais que forjaram a luta por direitos e modos de relação que, em muito, extrapolam a díade homem-mulher. É inegável o lugar de destaque dos movimentos feministas nas conquistas civilizatórias do século XX. No contexto contemporâneo atual de transição, uma vez mais, novos estilos de poder, liderança e gestão, mais femininos, humanos e inclusivos se fazem indispensáveis. Trata-se de uma agenda civilizatória da humanidade. 


\section{REFERÊNCIAS}

ARVATEA, P. R.; GALILEAB, G. W.; TODESCATC, I. The queen bee: A myth? The effect of top-level female leadership on subordinate females. The Leadership Quarterly, v. 29, n. 5, p. 533-548, out. 2018.

BERTIOL, M. I. S. Ser administradora é o feminino de ser administrador? In: ENCONTRO DA ASSOCIAÇÃO NACIONAL DE PÓS-GRADUAÇÃO EM ADMINISTRAÇÃO, 24. 2000, Atibaia. Anais... Atibaia: ENANPAD, 2000. 1 CD-ROM.

CARVALHO, M. D.; CARVALHO, J. D.; CARVALHO, F. A. O Ponto de Vista Feminino na Reflexão Ética: Histórico e Implicações para a Teoria de Organizações. In: ENCONTRO DA ANPAD, 25., 2001, Campinas. Anais... Campinas: ANPAD, 2001.

DERKS, B.; LAARB, C. V.; ELLEMERS, N. The queen bee phenomenon: why women leaders distance themselves from junior women. The Leadership Quarterly, v. 27, n. 3, p. 456-469, jun. 2016.

EAGLY, A.; CARLI, L. L. Women and the Labyrinth of Leadership. Harvard Business Review, p. 62-71, set. 2007.

HARAWAY, D. Gênero para um dicionário marxista: a política sexual de uma palavra. Cad. Pagu, Campinas, n. 22, p. 201-246, jan./jun. 2004. Disponível em: <https://doi.org/10.1590/S0104-83332004000100009>. Acesso em: 28 maio 2020.

HIRATA, H.; KERGOAT, D. Novas configurações da divisão sexual do trabalho. Caderno de pesquisa, v. 37, n. 132, p. 595-609, set./dez. 2007.

HURLEY, A. E. "Incorporating feminist theories into sociological theories of entrepreneurship". Women in Management Review, v. 14, n. 2, p. 54-62, 1999.

HRYNIEWIC, L. G. C.; VIANNA, M. A. Mulheres em posição de liderança: obstáculos e expectativas de gênero em cargos gerenciais. Caderno EBAPE.BR, Rio de Janeiro, v. 16, n. 3, p. 331-344, jul./set. 2018.

INSTITUTO BRASILEIRO DE GEOGRAFIA E ESTATÍSTICA - IBGE. Pesquisa nacional por Amostra de Domicílios Contínua - PNAD C. Rio de Janeiro: IBGE, 2017.

IRIGARAY, H. A. R. Orientação Sexual e Trabalho. GV Executivo, v. 10, n. 2, p. 44-47, 2011.

JESUS, J. G. Orientações sobre identidade de gênero: conceitos e termos. Brasília, DF: [s.n.], 2012. Disponível em: <http://www.diversidadesexual. com.br/wp-content/uploads/2013/04/G\%C3\%8ANERO-CONCEITOSE-TERMOS.pdf>. Acesso: em 20 abr. 2017.

KANAN, L. A. Poder e liderança de mulheres nas organizações de trabalho. Revista Organizações \& Sociedade, v. 17, n. 53, p. 243257, abr./jun. 2010.
LEE, L. E. et al. Women on boards: global trends in gender diversity on corporate boards. New York: MSCl, 2018. (Research Insights).

MAVIN, S.; BRYANS, P. Gender on the agenda in management education?. Women In Management Review, v. 14, n. 3, p. 99-104, 1999. Disponível em: <http://doi.org/10.1108/09649429910269901>. Acesso em: 28 maio 2020.

MELO, H. P.; THOMÉ, D. Mulheres e Poder. Rio de Janeiro: Ed. FGV, 2018.

NOGUEIRA, E. C. Sentidos do Exercício da Liderança por Mulheres Executivas Brasileiras. 2012. Dissertação (Mestrado em Administração) - Universidade Municipal de São Caetano do Sul, São Paulo, 2012.

OLIVEIRA, F. B.; MENEZES, M.; SANT'ANNA, A. S. Percepções sobre os valores das mulheres no mercado de trabalho. In: CONGRESO INTERNACIONAL DEL CLAD, 17., 2012, Caracas. Anais... Caracas: CLAD, 2012.

OLIVEIRA, R. Elogio da diferença: O feminino Emergente. Brasiliense, 1993.

PEREZ-NEBRA, A.R; TORRES, C. Diversidade e inclusão nas organizações. In: ZANELLI, J. C; BORGES-ANDRADE, J. E; BASTOS, A. V. B (Orgs.). Psicologia, Organizações e Trabalho no Brasil. Porto Alegre, Artmed, 2014.

SANT'ANNA, A. S.; MELLO, A. M. G. Remuneração Femina. São Paulo: Aliança para o Empoderamento das Mulheres, 2018 - ONU Mulher. (Relatório de Pesquisa).

SIQUEIRA, A. C. F.; SALES, R, G.; FISCHER, R. M. Diversidade nas Organizações: Uma Análise Sistemática da Produção Acadêmica da Área de Administração entre 2010 e 2015. In: ENCONTRO DA ANPAD, 40., 2016, Salvador. Anais... Salvador: ANPAD, 2016.

SCHWAB, K. A quarta revolução industrial. São Paulo: EDIPRO, 2016.

SCOTT, J. Gender: A useful category of historical analysis. The American Historical Review, v. 91, n. 5, p. 1053-1101, 1986.

SUSSKIND, R.; SUSSKIND, D. The future of the professions: how technology will transform the work of human experts. Glasgow: Oxford Press, 2017.

TAJFEL, H.; TURNER, J. C. An integrative theory of intergroup conflict. In: WORCHEL, S.; AUSTIN, W. G. (Eds.). The Social Psycology of Intergroup relations. Chicago: Nelson Hall, 1979.

TEIXEIRA, S. Gestão das Organizações. Madrid: McGrawHill, 2005.

TEIXEIRA, S. Gestão das Organizações. Madrid: McGrawHill, 1998. 
Renata Kessler Miltersteiner

ORCID: https://orcid.org/0000-0003-4884-4133

Mestre em Administração Pública pela Escola Brasileira de Administração Pública e de Empresas da Fundação Getulio Vargas (FGV EBAPE); Coordenadora de Planejamento Financeiro na Secretaria de Estado de Fazenda do Estado do Rio de Janeiro, Rio de Janeiro - RJ, Brasil. Pesquisadora de Gênero e Liderança Feminina. E-mail: renata.mil@gmail.com

\section{Fátima Bayma de Oliveira}

ORCID: https://orcid.org/0000-0001-5158-9546

Doutora em Educação pela Universidade Federal do Rio de Janeiro (UFRJ); Professora Titular da Fundação Getulio Vargas nos cursos de Mestrado e Doutorado em Administração na Escola Brasileira de Administração Pública e de Empresas (FGV EBAPE), Rio de Janeiro - RJ, Brasil. E-mail: fatima.oliveira@fgv.br

\section{Lygia Gonçalves Costa Hryniewicz}

\section{ORCID: https://orcid.org/0000-0001-5553-0955}

Pesquisadora no Nucleo de Pesquisa em Estratificacao e Trajetorias Sociais da Universidade Federal do Rio de Janeiro (PATHS/UFRJ); Doutorado em Sociologia pela Sociedade Brasileira de Instrução no Instituto Universitário de Pesquisas do Rio de Janeiro (SBI/IUPERJ); Pós-Doutorado no Instituto de Pesquisa e Planejamento Urbano e Regional da Universidade Federal do Rio de Janeiro (IPPUR/UFRJ). E-mail: Iygcosta@gmail.com

\section{Anderson de Souza Sant'Anna}

\section{ORCID: https://orcid.org/0000-0001-6537-6314}

Pós-doutor em Teoria Psicanalítica pela Universidade Federal do Rio de Janeiro (UFRJ); Doutor em Administração e Doutor em Arquitetura e Urbanismo pela Universidade Federal de Minas Gerais (UFMG); Professor Adjunto da Escola de Administração de Empresas de São Paulo da Fundação Getulio Vargas (FGV EAESP), São Paulo - SP, Brasil. E-mail: anderson.santanna@fgv.br

Luiz Carlos Moura

ORCID: https://orcid.org/0000-0001-8543-231X

Doutorando em Administração pela Escola Brasileira de Administração Pública e de Empresas da Fundação Getulio Vargas (FGV EBAPE); Professor colaborador da Faculdade de Administração e Ciências Contábeis da Universidade Federal do Rio de Janeiro (UFRJ), Rio de Janeiro - RJ, Brasil. E-mail: Icarlos_moura@hotmail.com 